\title{
Knowledge and practice characteristics of pharmacists in Qatar towards medication use in pregnancy: a cross-sectional survey
}

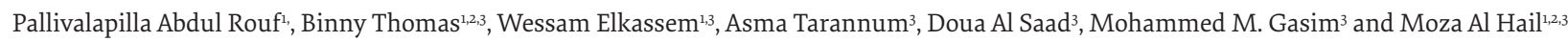

1Corporate Pharmacy, Hamad Medical Corporation, Doha, Qatar (Correspondence to: Binny Thomas: binnyinhmc@gmail.com; b.thoması@rgu.ac.uk). ${ }^{2}$ Robert Gordon University, Aberdeen, United Kingdom. ${ }^{3}$ Women's Hospital, Hamad Medical Corporation, Doha, Qatar.

\begin{abstract}
Background: Medication use during pregnancy is common. Pharmacists have an important role in improving medication use during pregnancy. There is a lack of empirical evidence on pharmacists' knowledge and practice characteristics towards medication use in pregnancy.

Objectives: This study aimed to determine the knowledge and practice characteristics of pharmacists in Qatar about medicines use in pregnancy.

Methods: A cross-sectional, questionnaire-based study was conducted over a period of 6 months in 2010. Questionnaires were distributed to 400 of 800 licensed pharmacists employed in Qatar (in government and private sectors). Data were collected on: demographics and practice characteristics of the pharmacists; their knowledge and perception about medication use in pregnancy; their confidence in dealing with pregnant women and physicians; and their source of the drug information.

Results: Of the 400 questionnaires distributed, 207 were returned (52\% response rate). Most pharmacists (71\%) had not participated in any educational activities on medication use in pregnancy. About $50 \%$ reported that $<10 \%$ of their workload involved dispensing medications to pregnant women. A lack of available resources and unknown pregnancy status were the main concerns about dispensing medication to pregnant women. The majority of the respondents had average knowledge about medication use in pregnancy. There was a significant association between knowledge, and continuing education and years of experience $(P<0.05)$.
\end{abstract}

Conclusions: Pharmacists in Qatar had an average level of knowledge about medications use in pregnancy. Continuous educational programmes are needed for pharmacists in Qatar to enhance their knowledge and practice of medicine use during pregnancy.

Keywords: Pregnancy, pharmacist, knowledge, medication, continuous education

Citation: Pallivalapilla AR; Thomas B; Elkassem W; Tarannum A; Al Saad D; Gasim MM; et al. Knoweldge and practice characteristics of pharmacists in Qatar about medication use in pregnancy: a cross-sectional survey. East Mediterr Health J. 2018;24(2):137-145. https://doi.org/10.26719/2018.24.2.137.

Received: 28/09/16; accepted: 16/02/17

Copyright $@$ World Health Organization (WHO) 2018. Some rights reserved. This work is available under the CC BY-NC-SA 3.0 IGO license (https:// creativecommons.org/licenses/by-nc-sa/3.o/igo).

\section{Introduction}

Maternal health refers to the health of women pre-pregnancy, during pregnancy, childbirth and postpartum (1). Medication use during pregnancy is challenging because of the potential fetal risk associated with the use of medications. Given the maternal physiological changes during pregnancy, women suffer from a variety of symptoms, such as nausea and vomiting, constipation, indigestion, hypertension, eclampsia and infections, for which medication use may be unavoidable at times (2). Although a number of medications used during pregnancy are known to cause fetal harm, there is still a lack of data on the risk and safety of the vast majority of medications. Because of this, pregnant women might unknowingly take a medication that could affect her fetus, or the anxiety and overestimated risk perception may discourage women from adhering to beneficial regimens (3).

Medication use during pregnancy is common (2). Approximately $40 \%$ of all pregnancies worldwide are unplanned, representing about 85 million women (4), and most of these women have used medicines before their pregnancy is known. Global data suggest that $27 \%$ to $93 \%$ of all women use at least one prescription drug during pregnancy (5). A study in the United States of America (USA) found that in $88 \%$ of all pregnancies, women used at least one medication, either prescribed or over the counter (6). In Europe, the prevalence of prescribed medications during pregnancy varied considerably across countries, ranging from $26 \%$ in Serbia to $93 \%$ in France (7-9). In a recent study in Saudi Arabia, about 40\% of all pregnant women were reported to have used either herbal or conventional medicines (10) while in Oman, a high prevalence in overall use of medications during pregnancy compared with the prepregnancy period was reported (11). No similar data have been published for Qatar.

Pharmacists are medication experts, well trained to apply evidence-based clinical knowledge, provide 
pharmaceutical care and advise women on their prescriptions (12). Some patients approach pharmacists as the first step in seeking medical advice for their symptoms (13). Furthermore, studies have identified pharmacists as a primary health care provider in answering drug-related queries and counselling pregnant women on their medications $(13,14)$. However, pharmacists may not have the information and skills to provide appropriate advice. A study in the USA, which explored pharmacists' interpersonal skills and ability to propose appropriate therapeutic plans, reported that community pharmacist lacked appropriate knowledge and skills to provide pharmaceutical care (15). In a similar study in Saudi Arabia on awareness about drug safety and use of medications during pregnancy, more than $70 \%$ of pregnant women were confident about the information provided by pharmacists; however fewer than $18 \%$ had received any medication-related information from their pharmacists (16).

Pharmacy practice settings include pharmacy services in hospitals, polyclinics, primary health care services and community pharmacies (17). About 800 licensed pharmacists were employed in Qatar in 2010 (18). Dispensing of prescriptions remains the primary duty of pharmacists in Qatar, particularly in community pharmacies with no clinical pharmacy services. There are no mandatory instructions to provide patients with medication use information or counsel them on any new prescriptions.

Improvement of any health care services requires a clear understanding of the characteristics and knowledge of the health care workforce. As in other developing countries, pharmacy practice in Qatar is evolving rapidly; however, there is a lack of empirical evidence about pharmacists' knowledge, practice and experience of drug use in pregnancy. Therefore, our research aimed to determine if the pharmacy workforce in Qatar was sufficiently trained and prepared to dispense medications to pregnant women.

The primary research objectives were to determine the knowledge, practice and confidence of pharmacists in Qatar about drug use in pregnancy. The secondary objectives was to determine the association between their knowledge, and their experience and continuing education.

\section{Methods}

\section{Design and setting}

A cross-sectional, descriptive, questionnaire-based study was conducted by the pharmacy department of the Women's Hospital of the Hamad Medical Corporation from June to December 2010. All licensed pharmacists working in hospitals, community pharmacies, primary care centres and polyclinics were eligible for inclusion.

\section{Sample size}

A convenience sampling technique was used to recruit the pharmacists. Raosoft ${ }^{\circledast}$ online calculator was used to calculate the sample size (19). Based on this, a sample size of 300 pharmacists was required for a confidence level of $95 \%$ and a $5 \%$ margin of error. However, 400 pharmacists were included in the final survey to add strength to the study and compensate for pharmacists failing to submit the questionnaire or submitting incomplete questionnaires.

\section{Questionnaire}

A 23-item self-completed anonymous questionnaire was developed and validated for the study. Most of the survey questions were adopted from previously validated surveys and tailored to meet the objectives of the current study (20-22). Previous questionnaire-based studies in Qatar have shown that surveys in English can be an effective tool to gather information from practising pharmacists in Qatar, even though the majority of pharmacists originate from Arabic-speaking countries $(20,23)$. A group of expert pharmacists (drug information pharmacists, pharmacy supervisors, and senior community pharmacists) were consulted to evaluate the content validity of the questionnaire. A pilot study was conducted with 30 pharmacists ( 16 community and 14 hospital pharmacists) and amendments were made wherever necessary.

The questionnaire had 4 sections.

- Section 1: demographic and pharmacy practice characteristics of the respondents (Q1-Q8), including age, gender, years of practice and participation in continuing education.

- Section 2: knowledge and perception of pharmacist about medication use during pregnancy (Q9-Q16). These questions had subdivisions giving a total of 28 questions. In this section, pharmacists were asked about the most frequent medications dispensed, their concerns while dispensing medication to pregnant women, safety of medication during pregnancy and drugs causing fetal harm. The respondents' knowledge levels were assessed using scores: +1 for every correct answer and o for wrong answers.

- Section 3: pharmacist's level of confidence while dealing with pregnant women, and physicians (Q17-Q20). This section mainly focused on how the participants identified pregnant women, how confident they were to advise them on medications and their confidence in contacting the prescribers (the woman's physician).

- Section 4: source of the drug information used (Q21Q23). This section identified the source of the drug information they provided while dispensing medication to pregnant women.

\section{Data collection}

A database was created of the 800 practising pharmacists in Qatar (both in the government and private sectors); the list of pharmacists was obtained from the licensing section of the Ministry of Public Health, Qatar. The questionnaire was distributed to 400 of these pharmacists.

Five pharmacists from the Women's Hospital were 
selected to distribute and collect the questionnaire (they were excluded from the study). Questionnaires were distributed personally to the pharmacists during the day shift. The pharmacy manager was also given questionnaires to give to any absentee pharmacists. Pharmacy technicians and pharmacists without a Qatari licence were excluded from the survey. Anonymously completed surveys were sent back to the principal investigator's (PAR) office at the Women's Hospital or collected from the drop box placed at every facility when the questionnaires were delivered, or were collected by a representative of the Women's Hospital. Three reminders were sent at 10-day intervals by email/telephone, and a representative of the Women's Hospital made frequent visits to all pharmacies. Several other strategies were used to maximize the response rate, including timely reminders to the managers to encourage their staff to complete the questionnaire, and sending the questionnaire to Hamad Medical Corporation hospitals with a cover letter and an addressed envelope to be returned through the internal mail system (24).

\section{Data analysis}

Descriptive statistics were used for all the variables. Data were analysed with SPSS, version 20 . The knowledge level of each respondent was determined by ranking their answers based on a scale with a maximum score of 28 (average knowledge for a score $\leq 15$, good knowledge for a score of $\geq 16$ to $\leq 24$ and very good knowledge for a score of $\geq 25$ ). To examine the association between knowledge, and experience and continuing education, the chisquared test was used. A $P$-value $\leq 0.05$ was considered statistically significant.

\section{Ethical considerations}

The study was approved by the Medical Research Center at Hamad Medical Corporation, MRC Protocol Number - MRC-10124.

\section{Results}

Of the 400 questionnaires distributed, 243 were returned in the 5 -week collection period. Of these, 12 had not been filled and 24 were incomplete; these were excluded from the final analysis. Hence a total of 207 questionnaires were included in the final analysis (52\% response rate), about $25 \%$ of the 800 licensed, practising pharmacist in Qatar at the time of the study.

\section{Demographics and practice}

The highest percentages of respondents were hospital pharmacists $(46.9 \%)$, followed by community pharmacists $(40.1 \%)$; only $13.0 \%$ responded from primary health care centres. About $50 \%$ of the pharmacists worked $\leq 40$ hours a week. The majority (95.7\%) had a bachelor's degree in pharmacy; only $3 \%$ had completed a postgraduate degree (Table 1). Most pharmacists were non-Qataris.

\section{Experience of pharmacists in Qatar}

Most of the respondents (79.2\%) had $\geq 5$ years of experience as a registered pharmacist. However, when asked about dispensing medication to pregnant women, almost half of the respondents (48.3\%) had less than a $10 \%$ workload in dispensing to pregnant women (Table 1).

\section{Continuing pharmacy education}

Over $50 \%$ of the pharmacists had less than 20 continuing pharmacy education credits or had received no continuing education in past 12 months (Table 1). Lack of time and workload were cited as the main reasons for not attending these educational activities by $66 \%$ of the respondents.

\section{Dispensing to pregnant women}

About three quarters (71\%) of the respondents had not had any educational activities on medication use in pregnancy during or after their Bachelor's/Master's pharmacy degree. About three quarters $(72 \%)$ considered that the best way to identify a pregnant patient was to have a pregnancy status written on the prescription. The majority of the respondents $(86 \%)$ were aware of the risks and benefits associated with medication use in pregnancy; about $80 \%$ stated that their work experience made them aware of the risk-benefits.

When asked how comfortable they were giving advice to pregnant women on medication, $66.2 \%$ were "very comfortable" to "somewhat comfortable", $24.2 \%$ were neutral (neither comfortable nor uncomfortable) and $9.6 \%$ were uncomfortable. Their major concern while dispensing to pregnant women was not being aware of the stage of pregnancy (76.5\%) (Figure 1).

\section{Dispensed medications}

The most frequently dispensed medications were vitamins and anti-emetics (> 95\%); anti-epileptics, anti-lipidaemics, antidepressants and antipsychotics were the least dispensed $(\leq 3 \%)$ (Table 2 ).

\section{Knowledge levels of pharmacists in Qatar}

Most of the respondents (64.7\%) had average knowledge levels, while only a few (1\%) had very good knowledge (i.e. respondents who scored more than $25 / 28$ points).

\section{Drug information resources used}

Most of the respondents used the point of care references. The most common drug information resources used by the pharmacists were the British National Formulary (77.8\%), followed by Micromedex (52.3\%) and Pregnancy specific books (32.3\%) (Figure 2).

\section{Knowledge and experience}

Years of practice in Qatar significantly affected the pharmacists' knowledge levels. Approximately $60 \%$ of pharmacists with 5-9 years of experience had good knowl- 


\begin{tabular}{|c|c|c|}
\hline Variable & No. & $\%(n=207)$ \\
\hline \multicolumn{3}{|l|}{ Gender } \\
\hline Male & 114 & 55.1 \\
\hline Female & 93 & 44.9 \\
\hline \multicolumn{3}{|l|}{ Practice } \\
\hline Hospital pharmacy & 97 & 46.9 \\
\hline Primary health care & 27 & 13.0 \\
\hline Community pharmacy & 83 & 40.1 \\
\hline \multicolumn{3}{|l|}{ Place of practice } \\
\hline Women's Hospital pharmacy & 36 & 17.4 \\
\hline Al Amal Hospital pharmacy & 8 & 3.9 \\
\hline Al Rumailah Hospital pharmacy & 13 & 6.3 \\
\hline Hamad General Hospital pharmacy & 33 & 15.9 \\
\hline Community pharmacies & 73 & $35 \cdot 3$ \\
\hline Polyclinic & 10 & 4.8 \\
\hline Primary health care centre & 27 & 13.0 \\
\hline Al Khor Hospital pharmacy & 7 & 3.4 \\
\hline \multicolumn{3}{|l|}{ Qualification } \\
\hline Bachelor's degree & 198 & 95.7 \\
\hline Master's degree & 8 & 3.9 \\
\hline Other (e.g. continuing pharmacy education) & 1 & 0.5 \\
\hline \multicolumn{3}{|l|}{ Experience (years) } \\
\hline$<5$ & 43 & 20.8 \\
\hline $5-9$ & 86 & 41.5 \\
\hline$>10$ & 78 & 37.7 \\
\hline \multicolumn{3}{|l|}{ Hours per week } \\
\hline$\leq 40$ & 95 & 45.9 \\
\hline 48 & 59 & 28.5 \\
\hline$\geq 50$ & 52 & 25.1 \\
\hline \multicolumn{3}{|l|}{ Dispensing workload to pregnant women (\%) } \\
\hline$<10$ & 100 & 48.3 \\
\hline $1-20$ & 38 & 18.4 \\
\hline$>20$ & 52 & 25.1 \\
\hline Don't know & 17 & 8.2 \\
\hline \multicolumn{3}{|l|}{ Continuing pharmacy education (hours) } \\
\hline $1-20$ & 55 & 26.6 \\
\hline $21-30$ & 39 & 18.8 \\
\hline $31-40$ & 26 & 12.6 \\
\hline$>40$ & 30 & 14.5 \\
\hline None $^{\mathrm{a}}$ & 57 & 27.5 \\
\hline
\end{tabular}

edge (scores $\geq 16$ and $\leq 24$ ), which was significantly higher than the pharmacists who had less than 5 years of experience $(P<0.001)$.

\section{Knowledge and continuing pharmacy education}

There was a significant correlation between knowledge and continuing education; about $60 \%$ of the pharmacists who had good knowledge had attended 40 or more hours of continuing educational activities in comparison with $19 \%$ of the pharmacists who had no continuing pharmacy education points $(P<0.001)$.

\section{Experience and continuing pharmacy education}

During the first 5 years of employment, only 3.3\% of pharmacists had more than 40 continuing pharmacy education points, whereas $56 \%$ of pharmacists with 5-9 years 
of experience had more than 40 continuing pharmacy education credits. However, about $44 \%$ of pharmacists with $\geq 10$ years' experience had no continuing pharmacy education credits $(P<0.001)$.

\section{Confidence in giving information to patients and physicians}

Only $33.3 \%$ of the respondents were very comfortable giving advice/counselling to pregnant women, however $89 \%$ (strongly agreed and agreed) believed that they were competent enough to inform pregnant women about their medication. Similarly, about $81 \%$ [strongly agreed (30.9\%) and agreed (50.2\%)] of the respondents believed that they were competent enough to inform physicians about the risks and benefits of medications used in pregnancy.

There was no significant correlation between pharmacist's length of experience and their confidence to inform patients about the risks and benefits of their medication; however with more experience they were more confident to inform physicians about risks and benefits $(P=0.38$ and $P<0.001$ respectively).

\section{Discussion}

A literature review of the past 10 years did not identify any similar studies from Qatar assessing the knowledge, experience, confidence and practice of pharmacist in Qatar while dispensing medications to pregnant women.

The main findings of the study suggest that a majority of the respondents had an average level of knowledge about medications used during pregnancy. Most of the pharmacists had 5 or more years of experience; however, almost $50 \%$ of them had very little experience in dispensing medications to a pregnant woman. The study also showed that pharmacists in Qatar lacked participation in continuing education programmes. Although most of them felt confident to advise physicians on medications used in pregnancy, a good proportion was not comfortable about doing so for pregnant women.

The response rate was $52 \%$ and the highest percentage of respondents were hospital pharmacists, mostly from Hamad Medical Corporation. The response rate was in line to the results obtained from other pharmacist surveys in Qatar $(20,22)$. The majority of the pharmacists had a bachelor's degree in pharmacy, and most of them had 5 or more years of working experience. For about half of the respondents less than $10 \%$ of their workload involved dispensing medications to pregnant women. This might be because most pregnant women are reviewed, treated and followed up at primary health care centres and the Women's Hospital. Respondents for whom dispensing to pregnant women represented more than $20 \%$ of their workload were pharmacists at the Women's Hospital.

Almost one third of the respondents had no continuing pharmacy education. More than $50 \%$ of the respondents stated that they had received less than 20 hours of continuing educational sessions in a year. This result demonstrates the relevance and importance of continuing pharmacy educations sessions as an important area of pharmacy practice. The main reasons for not attending continuing pharmacy education were workload and the timing of the activities that were either during their busy working hours or on their off days. This result is similar to earlier studies done in Qatar and Saudi Arabia $(25,26)$. Moreover, there were no obligatory continuous educational activities while this study took place. However, from 2015, the Qatar Council for Healthcare Practitioners mandated that every heath professional had to attend educational activities for the renewal of his/her practice licence (27).

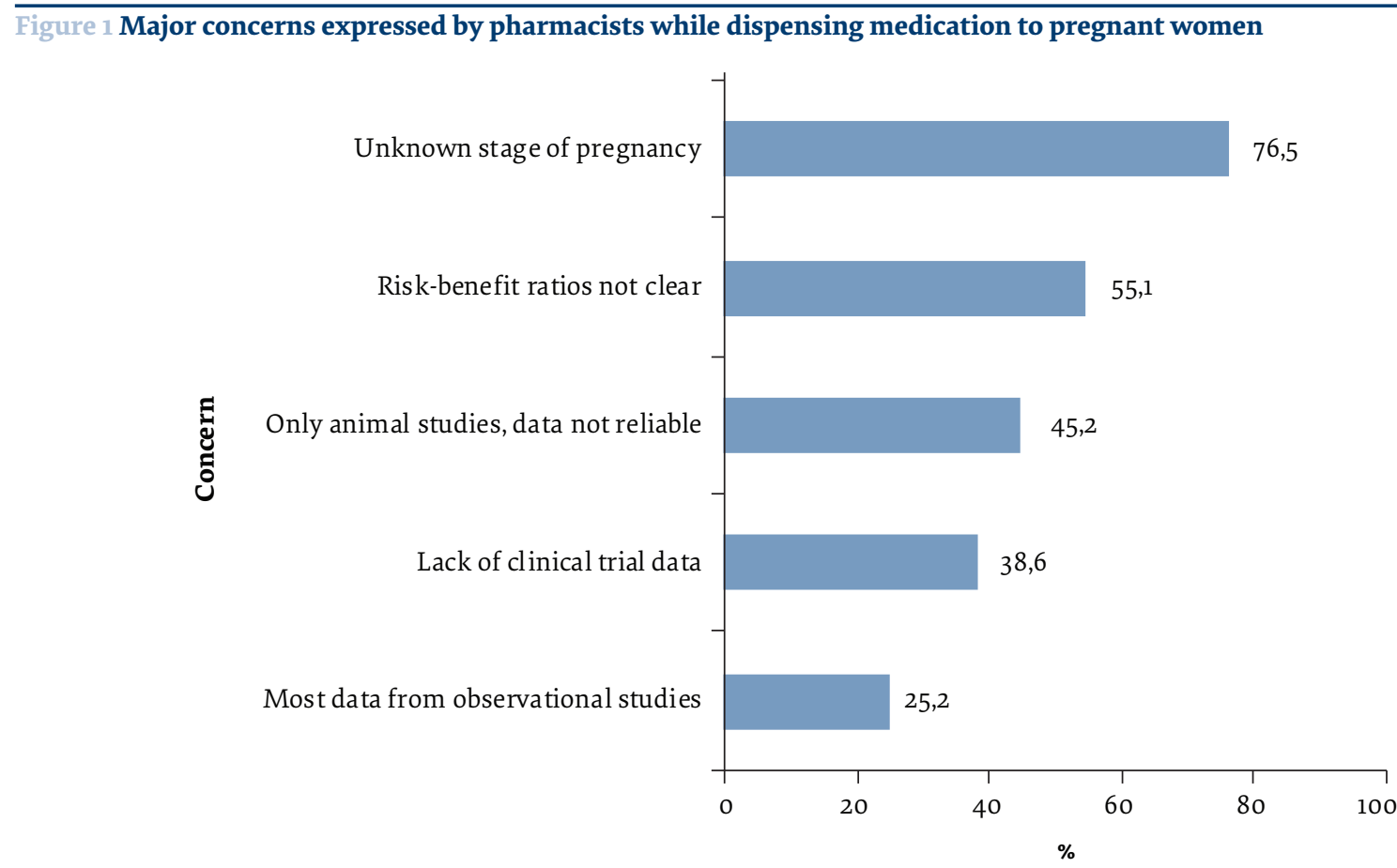




\begin{tabular}{|c|c|}
\hline $\begin{array}{l}\text { Which of these medications do you } \\
\text { dispense most frequently? }\end{array}$ & $\begin{array}{c}\text { No. }(\%) \\
(n=207)\end{array}$ \\
\hline Analgesics & $149(72.0)$ \\
\hline Antacids & $185(89.4)$ \\
\hline Antimicrobials & $54(26.1)$ \\
\hline Antidepressants & $13(6.3)$ \\
\hline Antidiabetics & $45(21.7)$ \\
\hline Antiemetics & $198(95.7)$ \\
\hline Laxatives & $139(67.1)$ \\
\hline Antihypertensive & $52(25.1)$ \\
\hline Antiepileptics & $4(1.9)$ \\
\hline Insulin & $63(30.4)$ \\
\hline Antihistamines & $64(30.9)$ \\
\hline Antiasthmatics & $23(11.1)$ \\
\hline Antilipidemic & $6(2.9)$ \\
\hline Antipsychotics & $5(2.4)$ \\
\hline Vitamins & $200(96.6)$ \\
\hline
\end{tabular}

In our evaluation of pharmacists' knowledge about drug use in pregnancy, the majority of them had average knowledge. This might be because of the lack of continuing pharmacy education or the lack of experience in dispensing to pregnant women. Our result is similar to a study that compared knowledge levels among pharmacist in Qatar, Canada and Uganda (28).

The pharmacists preferred to identify a pregnant women based on the pregnancy status written on the prescription, although this is not a standard practice in Qatar, which should possibly alarm the hospital policymakers as specialized maternity hospitals like the Women's Hospital require physicians to record pregnancy status on every prescription they write. The majority of the respondents felt able to assess the risk-benefit ratio while dispensing medication to pregnant women. The average level of knowledge of most pharmacists might be the reason why most were not very comfortable advising a pregnant woman on medication. Similar findings were reported from Tanzania (29). As, globally, 40\% of pregnancies are unplanned (4), a woman often discovers her pregnancy while taking regular medications and may visit a pharmacy to enquire if she has harmed her baby by this action. A pharmacist is therefore expected to have sound knowledge about drugs to be used in pregnancy. However, despite the recognized role of pharmacists as medication experts, studies have shown that they lack knowledge and confidence while advising pregnant women $(12,30)$.

Furthermore, researchers have highlighted the importance of continuing pharmacy educational programmes $(22,28,31)$. As demonstrated in our study, of the pharmacists who had good knowledge, $60 \%$ had had more than 40 hours of continuing education in a year. This shows a significant positive association between continuing education and knowledge. Similarly, pharmacists with 5 or more years of experience scored better than those with less experience. Our study calls for structured continuing pharmacy educational programmes to be introduced in Qatar to ensure that pharmacists have the necessary updated information, education and skills to provide competent pharmaceutical care.

There were some limitations to our study and hence the results should be interpreted with caution. Despite all the strategies used to maximize participation, the response rate was low (52\%). The reasons for nonparticipation are unknown, although we think it may be because of the length of the survey, or lack of interest or time. The questionnaire was distributed only during the day shift and it is possible that pharmacists who completed it could have had a better understanding, knowledge and confidence about drug use in pregnancy

Figure 2 Resources used by pharmacists to answer drug information for pregnant women

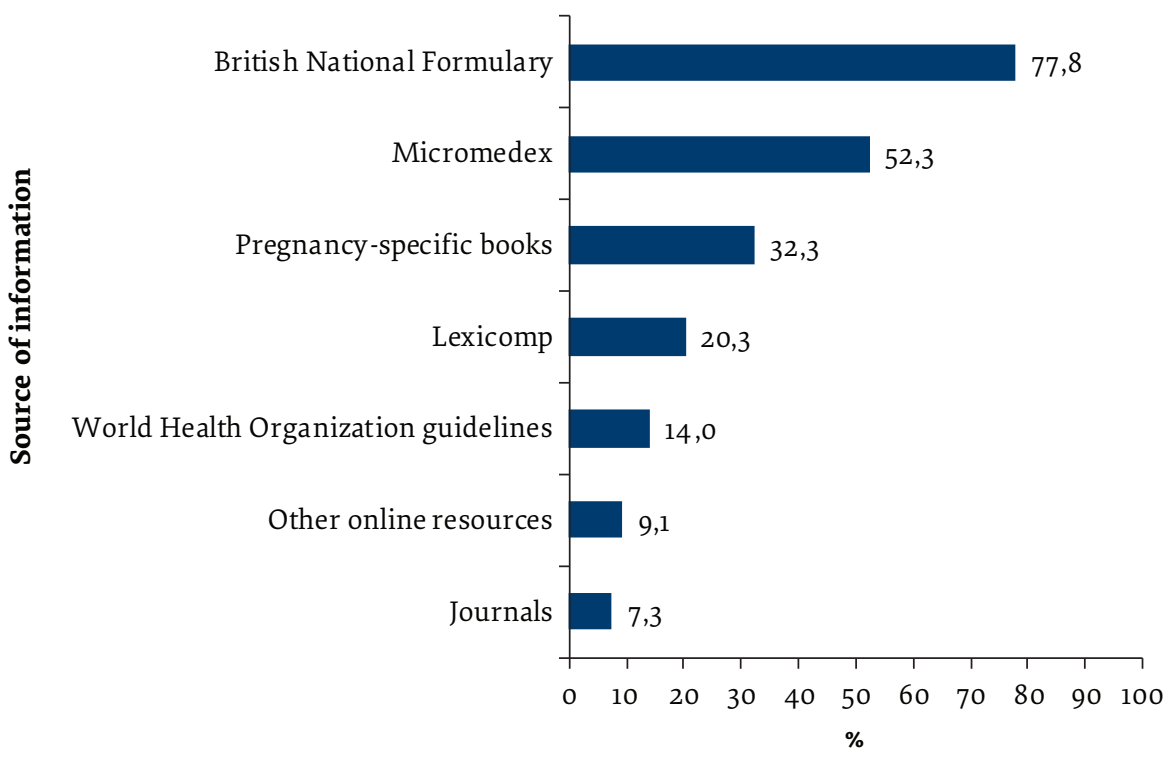


than pharmacists in other shifts (response bias). Furthermore, there is a potential for social desirability bias since the findings are based on self-reports. The survey was completed on hard copy and there is a possibility of information exchange between the respondents while answering the knowledge questions. Although the demographics of our sample were similar to the total pharmacist population, the findings may not be generalizable in terms of knowledge because Women's Hospital respondents have specialized training in maternity medication use and might therefore have scored much higher on the knowledge questions than other pharmacists.

\section{Conclusion}

The study provides baseline data on the knowledge, practice characteristics and experience of pharmacists in Qatar about medication use in pregnancy. Although it was conducted in 2007 and changes may have occurred, medication use during pregnancy is prevalent and there is still a lack of data on the knowledge, attitude and practice of pharmacists in Qatar towards medication use in pregnancy. To the best of our knowledge, no similar stud- ies have been published in the region to date. With the majority of respondents having an average knowledge and lacking continuous educational activities, there is a need to introduce continuous education programmes to fill knowledge gaps of pharmacists on medications used in pregnancy. Our study in fact led to several continuing professional development activities on medication use during pregnancy, accredited by the Qatar Council of HealthCare Practitioners (official body for accrediting continuing professional development providers in Qatar). Our study also highlights the importance of overcoming several other obstacles faced by pharmacists in Qatar while giving drug information to pregnant women, such as lack of time and lack of training in drugs used during pregnancy. As women take different medications during pregnancy, both prescription and over-the-counter drugs, including complementary and traditional medications, it is important to understand their knowledge about the use of such products in pregnancy. Therefore, further research is needed to identify the attitude, perception and knowledge of pregnant women themselves about the medications they use during pregnancy.

\section{Acknowledgements}

We acknowledge the support of all the participants for completing and returning the questionnaire. We further appreciate and thank pharmacists at the Women's Hospital who distributed the questionnaire. The research team is thankful to Dr. Afif Ahmed (Assistant Director, Clinical Pharmacy Services) for all his support and guidance during the project.

Funding: This study was funded by the Medical Research Centre (MRC), Hamad Medical Corporation, Qatar.

Competing interests: None declared.

\section{Connaissances et caractéristiques des pratiques des pharmaciens qataris en matière d'utilisation des médicaments pendant la grossesse : étude transversale}

\section{Résumé}

Contexte : L'utilisation des médicaments durant la grossesse est courante. Les pharmaciens jouent un rôle important dans l'amélioration de l'utilisation des médicaments pendant cette période Les données empiriques manquent sur les connaissances des pharmaciens et leurs pratiques en la matière.

Objectifs : La présente étude visait à déterminer les connaissances et les caractéristiques des pratiques des pharmaciens qataris en matière d'utilisation des médicaments pendant la grossesse.

Méthodes : Une étude transversale, reposant sur un questionnaire, a été conduite sur une période de six mois en 2010. Des questionnaires ont été distribués à 400 des 800 pharmaciens agréés exerçant au Qatar (dans les secteurs public et privé). Des données ont été recueillies sur les caractéristiques démographiques et concernant la pratique des pharmaciens, sur leurs connaissances et leur perception de l'utilisation des médicaments pendant la grossesse, sur leur confiance lorsqu'ils s'occupent de femmes enceintes et contactent les médecins prescripteurs, et sur les sources des informations qu'ils détenaient sur les médicaments.

Résultats : Sur les 400 questionnaires distribués, 207 ont été renvoyés (taux de réponse de $52 \%$ ). La plupart des pharmaciens (71 \%) n'avaient jamais participé à aucune activité de formation sur l'utilisation des médicaments pendant la grossesse. Environ 50 \% ont rapporté que moins de 10 \% de leur charge de travail impliquait la délivrance de médicaments aux femmes enceintes. Un manque de ressources disponibles et l'ignorance de l'état de grossesse des clientes étaient les principales préoccupations liées à la délivrance de médicaments aux femmes enceintes. La majorité des répondants avaient une connaissance moyenne de l'utilisation des médicaments pendant la grossesse. Il existait une association significative entre les connaissances, la formation continue et les années d'expérience $(p<0,05)$.

Conclusions : Les pharmaciens qataris avaient un degré de connaissance moyen de l'utilisation des médicaments pendant la grossesse. Des programmes de formation continue sont requis pour les pharmaciens qataris de façon à améliorer leurs connaissances et leurs pratiques en matière d'utilisation des médicaments pendant la grossesse. 


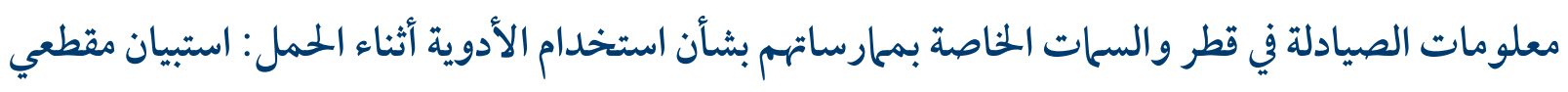

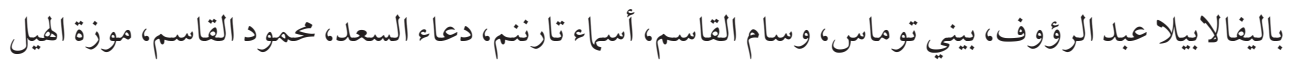

$$
\begin{aligned}
& \text { المعلومات الأساسية: ينبغي لجميع السياسات و البرامج الحكومية المعنية بالأمن الغذائي والتغذوي أن تشمل توفير الغذاء الصحي وإتاحته لجميع } \\
& \text { الناس بأسعار معقولة. }
\end{aligned}
$$

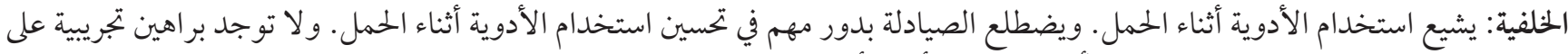

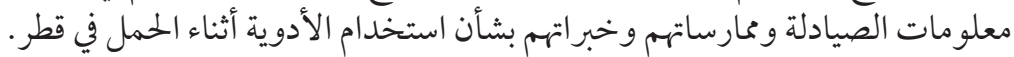

$$
\begin{aligned}
& \text { الأهداف: هدفت هذه الدراسة إلى تحديد معلومات الصيادلة في قطر والسمات الخاصة بممارساتهم بشأن استخدام الأدوية أثناء الحمل. }
\end{aligned}
$$

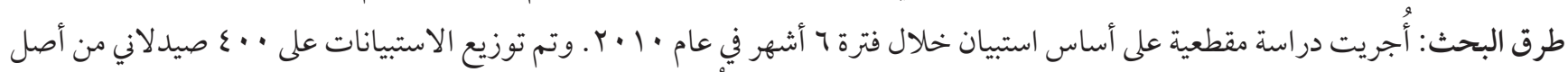

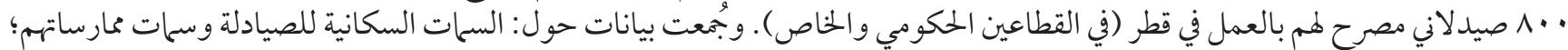

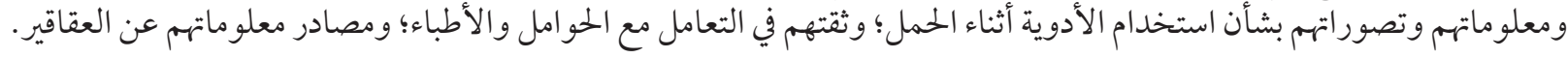

$$
\begin{aligned}
& (P<\cdot, \cdot 0)
\end{aligned}
$$

\section{References}

1. World Health Organization. Maternal and perinatal health [webpage]. (http://www.who.int/reproductivehealth/publications/maternal_perinatal_health/articles/en/, accessed 13 June 2016).

2. Bech BH, Kjaersgaard MI, Pedersen HS, Howards PP, Sørensen MJ, Olsen J, et al. Use of antiepileptic drugs during pregnancy and risk of spontaneous abortion and stillbirth: population based cohort study. BMJ. 201408 21;349 aug21 8:g5159. http://dx.doi. org/10.1136/bmj.g5159 PMID:25150301

3. McCarter-Spaulding DE. Medications in pregnancy and lactation. MCN Am J Matern Child Nurs. 2005 Jan-Feb;30(1):10-7, quiz 18-9. PMID:15622140

4. Hall JA, Barrett G, Copas A, Stephenson J. London Measure of Unplanned Pregnancy: guidance for its use as an outcome measure. Patient Relat Outcome Meas. 2017 Apr 6;8:43-56. http://dx.doi.org/10.2147/PROM.S122420 PMID:28435343

5. Daw JR, Hanley GE, Greyson DL, Morgan SG. Prescription drug use during pregnancy in developed countries: a systematic review. Pharmacoepidemiol Drug Saf. 2011 Sep;20(9):895-902. http://dx.doi.org/10.1002/pds.2184 PMID:21774029

6. Mitchell AA, Gilboa SM, Werler MM, Kelley KE, Louik C, Hernández-Díaz S, et al. Medication use during pregnancy, with particular focus on prescription drugs: 1976-2008. Am J Obstet Gynecol. 2011 Jul;205(1):51.e1-8. http://dx.doi.org/10.1016/j. ajog.2011.02.029 PMID:21514558

7. Odalovic M, Vezmar Kovacevic S, Ilic K, Sabo A, Tasic L. Drug use before and during pregnancy in Serbia. Int J Clin Pharm. 2012 Oct;34(5):719-27. http://dx.doi.org/10.1007/s11096-012-9665-8 PMID:22744842

8. Engeland A, Bramness JG, Daltveit AK, Rønning M, Skurtveit S, Furu K. Prescription drug use among fathers and mothers before and during pregnancy. A population-based cohort study of 106,000 pregnancies in Norway 2004-2006. Br J Clin Pharmacol. 2008 May;65(5):653-6o. http://dx.doi.org/10.1111/j.1365-2125.2008.03102.x PMID:18294334

9. Gagne JJ, Maio V, Berghella V, Louis DZ, Gonnella JS. Prescription drug use during pregnancy: a population-based study in Regione Emilia-Romagna, Italy. Eur J Clin Pharmacol. 2008 Nov;64(11):1125-32. http://dx.doi.org/10.1007/s00228-008-0546-y PMID:18685836

10. Zaki NM, Albarraq AA. Use, attitudes and knowledge of medications among pregnant women: A Saudi study. Saudi Pharm J. 2014 Nov;22(5):419-28. http://dx.doi.org/10.1016/j.jsps.2013.09.001 PMID:25473330

11. Al-Riyami IM, Al-Busaidy IQ, Al-Zakwani IS. Medication use during pregnancy in Omani women. Int J Clin Pharm. 2011 Aug;33(4):634-41. http://dx.doi.org/10.1007/s11096-011-9517-y PMID:21597985

12. Al Rahbi HA, Al-Sabri RM, Chitme HR. Interventions by pharmacists in out-patient pharmaceutical care. Saudi Pharm J. 2014 Apr;22(2):101-6. http://dx.doi.org/10.1016/j.jsps.2013.04.001 PMID:24648820. 
13. Alrabiah Z, Al-Arifi MN, Alghadeer SM, Wajid S, AlQahtani A, Almotari N, et al. Knowledge of community pharmacists about the risks of medication use during pregnancy in central region of Saudi Arabia. Saudi Pharm J. 2017 Nov;25(7):1093-1096. http://dx. doi.org/10.1016/j.jsps.2017.05.005 PMID:29158721

14. Odalović M, Milanković S, Holst L, Nordeng H, Heitmann K, Tasić L. Pharmacists counselling of pregnant women: web-based, comparative study between Serbia and Norway. Midwifery. 2016 Sep;40:79-86. http://dx.doi.org/10.1016/j.midw.2016.06.003 PMID:27428102.

15. Nduka SO, Anetoh MU, Amorha KC, Henry OO, Okonta MJ. Use of simulated patient approach to assess the community pharmacists' knowledge of appropriate use of metered dose inhaler. J Basic Clin Pharm. 2016 Sep;7(4):116-119. http://dx.doi. org/10.4103/0976-0105.189435 PMID:27999471.

16. A-Elbasit IEM, Abida, Alanazi AGS, Abdullah DA. Awareness about the drug safety and medication use among the pregnant women of the northern border region of Saudi Arabia. Indo Am J Pharm Sci. 2016;3(9):1054-61.

17. Sates of Qatar. Ministry of Public Health [website] (https://www.moph.gov.qa/, accessed 14 April 2016).

18. Hamad Medical Corporation. Annual health report, 2012. [homepage on the Internet]. cited 2016 April].

19. Raosoft sample size calculator (http://www.raosoft.com/samplesize.html, accessed 14 November 2017).

20. El Hajj MS, Al-Saeed HS, Khaja M. Qatar pharmacists' understanding, attitudes, practice and perceived barriers related to providing pharmaceutical care. Int J Clin Pharm. 2016 Apr;38(2):330-43. http://dx.doi.org/10.1007/s11096-016-0246-o PMID:26758716

21. Awaisu A, Mottram D, Rahhal A, Alemrayat B, Ahmed A, Stuart M, et al. Knowledge and Perceptions of Pharmacy Students in Qatar on Anti-Doping in Sports and on Sports Pharmacy in Undergraduate Curricula. Am J Pharm Educ. 2015 Oct 25;79(8):119. http://dx.doi.org/10.5688/ajpe798119 PMID:26689844

22. Stewart D, Al Hail M, Abdul Rouf PV, El Kassem W, Diack L, Thomas B, et al. Building hospital pharmacy practice research capacity in Qatar: a cross-sectional survey of hospital pharmacists. Int J Clin Pharm. 2015 Jun;37(3):511-21. http://dx.doi.org/10.1007/ S11096-015-0087-2 PMID:25733065

23. El Hajj MS, Kheir N, Zaidan M, Jewesson PJ. Pharmacist characteristics, medication use perceptions and professional satisfaction: a first national survey in the state of Qatar. J Healthc Leadersh. 2011;3:9-28. http://dx.doi.org/10.2147/JHL.S11700

24. Nakash RA, Hutton JL, Jørstad-Stein EC, Gates S, Lamb SE. Maximising response to postal questionnaires-a systematic review of randomised trials in health research. BMC Med Res Methodol. 200602 23;6(1):5. http://dx.doi.org/10.1186/1471-2288-6-5 PMID:16504090

25. Wilbur K. Continuing professional pharmacy development needs assessment of Qatar pharmacists. Int J Pharm Pract. 2010 Aug;18(4):236-41. http://dx.doi.org/10.1111/j.2042-7174.2010.00034.x PMID:20636676

26. Al-Ghamdi MS. Continuing pharmaceutical education for community pharmacists in the eastern province of Saudi Arabia. J Family Community Med. 2001 Sep;8(3):45-52. PMID:23008650

27. Qatar Council for Healthcare Practitioners. National CME/CPD Accreditation System [website] (http://www.qchp.org.qa/en/Pages/Home.aspx, accessed 14 November 2017).

28. Bains S, Kitutu FE, Rahhal A, Abu Samaha R, Wilby KJ, Rowe H. Comparison of pharmacist knowledge, perceptions and training opportunities regarding maternal-fetal medicine in Canada, Qatar and Uganda. Can Pharm J. 2014 Nov;147(6):345-51. http://dx. doi.org/10.1177/1715163514552558 PMID:25364351

29. Kamuhabwa A, Jalal R. Drug use in pregnancy: Knowledge of drug dispensers and pregnant women in Dar es Salaam, Tanzania. Indian J Pharmacol. 2011 May;43(3):345-9. http://dx.doi.org/10.4103/0253-7613.81503 PMID:21713045

30. Vanham D, Spinewine A. Conseils par le pharmacien d'officine lors de la délivrance de médicaments a la femme enceinte: étude d'observation [Evaluation of the quality of counseling provided by community pharmacists to pregnant women]. J Pharm Belg. 2010 Sep;(3):68-74. PMID:21090382

31. Tobaiqy M, Stewart D. Exploring health professionals' experiences of medication errors in Saudi Arabia. Int J Clin Pharm. 2013 Aug;35(4):542-5. http://dx.doi.org/10.1007/s11096-013-9781-o PMID:23649894 